Article

Subscriber access provided by King Abdullah University of Science and Technology Library

\title{
Dendritic Tip-on Polytriazine-Based Carbon Nitride Photocatalyst with High Hydrogen Evolution Activity
}

Manas K. Bhunia, Sigismund Melissen, Manas R Parida, Pradip Sarawade, Jean-Marie Basset, Dalaver H. Anjum, Omar F. Mohammed, Philippe Sautet, Tangui Le Bahers, and Kazuhiro Takanabe

Chem. Mater., Just Accepted Manuscript • DOI: 10.1021/acs.chemmater.5b02974 • Publication Date (Web): 23 Nov 2015

Downloaded from http://pubs.acs.org on December 8, 2015

\section{Just Accepted}

"Just Accepted" manuscripts have been peer-reviewed and accepted for publication. They are posted online prior to technical editing, formatting for publication and author proofing. The American Chemical Society provides "Just Accepted" as a free service to the research community to expedite the dissemination of scientific material as soon as possible after acceptance. "Just Accepted" manuscripts appear in full in PDF format accompanied by an HTML abstract. "Just Accepted" manuscripts have been fully peer reviewed, but should not be considered the official version of record. They are accessible to all readers and citable by the Digital Object Identifier (DOI®). "Just Accepted" is an optional service offered to authors. Therefore, the "Just Accepted" Web site may not include all articles that will be published in the journal. After a manuscript is technically edited and formatted, it will be removed from the "Just Accepted" Web site and published as an ASAP article. Note that technical editing may introduce minor changes to the manuscript text and/or graphics which could affect content, and all legal disclaimers and ethical guidelines that apply to the journal pertain. ACS cannot be held responsible for errors or consequences arising from the use of information contained in these "Just Accepted" manuscripts. 


\section{INTRODUCTION}

The design of an efficient hydrogen evolution photocatalyst based on abundant organic materials remains a key challenge for realizing a clean and sustainable solar fuel-based energy economy. ${ }^{1-12}$ Polymeric carbon nitride $(\mathrm{CN})$, initially reported by Berzelius and Liebig in 1834, has been found to be a stable organic photocatalyst for the photoredox splitting of water (half-reactions with suitable sacrificial reagents). ${ }^{13,14}$ The basic sub-unit would be either triazine or heptazine or even both interconnected through NH-bridges, resulting from the polycondensation of precursors such as dicyandiamide, cyanuric acid, melamine, and urea, with continuous elimination of $\mathrm{NH}_{3}{ }^{15,16}$ However, theoretical quantum chemical calculations have shown that structures containing heptazine motifs are thermodynamically more stable than those based on triazine units. ${ }^{17,18}$ Unlike kinetically limited solid state reactions, salt melt solution at high temperature synthesis leads to welldefined, crystalline, triazine-based polyimide networks. ${ }^{19,20}$ Although the optoelectronic and photocatalytic properties largely rely on the degree of polymerization, controlling of the planarity of the layers along with chain or surface termination are crucial in improving photocatalytic activity. Recently, we showed that an appropriate number and arrangement of dopants in the crystalline $\mathrm{CN}$ structure can enhance photocatalyt- ic activity. ${ }^{21}$ In particular; the crystallinity and the light harvesting in the visible range can be tuned to achieve high overall solar conversion efficiency. For triazine-based CN, however, the latest photocatalytic efficiency is still unsatisfactory for commercial realization, and the observed deactivation with time, of course, requires additional extensive research on its activity and stability. ${ }^{21}$

A variety of operational principles are encountered in the photocatalytic process, the fundamental steps being light absorption, exciton dissociation, charge-carrier diffusion and transport, and electrocatalytic redox reactions. ${ }^{22}$ In photocatalysis, particularly when using $\mathrm{CN}$ photocatalysts, morphology and surface area, in relation to the effective charge separation, are important parameters. ${ }^{23-30}$ Density functional theory (DFT) is a useful and powerful technique to obtain the relevant photophysical and optoelectronic parameters of a given photocatalyst. $^{31,32}$ In addition to structure determination, DFT calculations can lead to the simulation of several semiconductor properties such as the bandgap, the dielectric constants and band positions, with good accuracy thanks to recently developed functionals such as HSE06. ${ }^{33}$ Furthermore, the excitonbinding energy and effective masses of electrons and holes are very important parameters, accessible from calculations, in 
order to qualify a semiconductor as good photocatalytic material. $^{34}$

In this work, we combined experimental and theoretical studies to deeply understand the structural and electronic properties of visible-light-responsive $\mathrm{CN}$ materials. The polytriazine imide (PTI) crystal structure was obtained by copolymerization between melamine (Mel) and 2,4,6triaminopyrimidine (TAP), which enhances the visible light response. Detailed DFT calculations pin down the effects of TAP incorporation into the PTI structure for band structure and dielectric and optoelectronic properties. We also envisaged a strategy to improve the photocatalytic activity and stability of CN by introducing silica as support, while providing crystallinity along with improved light harvesting. Silica is often used as a hard template to produce a unique morphology of $\mathrm{CN}$ comprising a high surface area. ${ }^{35-38}$ Wang et al. recently reported the use of fibrous spherical KCC-1 silica particles ${ }^{39}$ as a hard template to produce porous and spherical heptazinebased CN with a large optical bandgap. ${ }^{35}$ To date, little attention has been given to elucidating the effects of silica as a support (without its removal) on $\mathrm{CN}$ photocatalysis. ${ }^{40-42} \mathrm{We}$ employed KCC-1 silica as a support for the flux-assisted synthesis of the PTI structure. This study clearly describes how to establish highly crystalline $\mathrm{CN}$ with a tunable bandgap, robust structural integrity and a slow charge carrier recombination rate, resulting in significant improvements in photocatalytic performance. A structural and kinetic understanding has been attempted by advanced high-resolution electron micrographs and time-resolved transient absorption spectroscopy.

\section{EXPERIMENTAL AND THEORETICAL METHODS}

Synthesis of Carbon Nitrides. Detailed synthesis procedure is described in the Supporting Information (SI). Typically, we used $1 \mathrm{~g}$ of melamine (Mel) and the required amount $(X$ $\mathrm{g}$, typically $0.15 \mathrm{~g}$ ) of 2, 4, 6-triaminopyrimidine (TAP) in various ratios as $\mathrm{CN}$ precursors. $\mathrm{KCC}-1$ silica was first acidified with $1 \mathrm{M} \mathrm{HCl}$ at a $60{ }^{\circ} \mathrm{C}$ temperature for $12 \mathrm{~h}$ because it is considered beneficial to coordinate strongly with the $\mathrm{CN}$ precursors and their organization before polycondensation. We mixed them together with acid-treated silica in absolute ethanol and stirred at $100{ }^{\circ} \mathrm{C}$ for $2-3 \mathrm{~h}$, yielding a light yellow powder. This solid powder was mixed and grinded with a eutectic mixture of $\mathrm{LiCl} / \mathrm{KCl}$ (59/41 mol ratio), transferred to a half-sealed crucible, rapidly heated to $550{ }^{\circ} \mathrm{C}$ in a muffle furnace (Nabertherm, L9/11/SKM), and kept at this temperature for $4 \mathrm{~h}$. After cooling to room temperature, the excess salt mixture was washed with boiling water, filtered, and then dried in an oven at $80{ }^{\circ} \mathrm{C}$ overnight. The obtained product is denoted as PTI- $X / \mathrm{KCC}-1$, where $X$ represents the amount of TAP relative to $1 \mathrm{~g}$ Mel. The sample with silica removal was

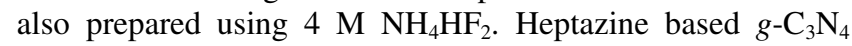
was also synthesized as a reference material, in accordance with the literature (see SI). ${ }^{13}$

Characterizations. The powder X-ray diffraction (XRD) patterns of the samples were collected with a Bruker D8 advance $\mathrm{X}$-ray diffractometer using $\mathrm{Cu} \mathrm{K} \alpha$ radiation $(\lambda=0.154$ $\mathrm{nm}$ ) operated at $40 \mathrm{kV}$ and $40 \mathrm{~mA}$ in the Bragg-Brentano geometry using a linear position-sensitive detector with an opening of $2.9^{\circ}$. A nickel filter to attenuate contributions from $\mathrm{Cu}-\mathrm{K}_{\beta}$ fluorescence.

Infrared (IR) spectra were recorded using a Perkin Elmer Spectrum 100 FTIR spectrometer with an attenuated total reflectance unit and a mid-infrared deuterated triglycine sul- fate (MIR- DTGS) detector. The spectra were obtained at a resolution of $4 \mathrm{~cm}^{-1}$ in the range of $4000-650 \mathrm{~cm}^{-1}$ and with the accumulation of 32 scans.

Optical diffuse reflectance spectra using the Kubelka-Munk function were collected at room temperature with a UV-Vis diffuse reflectance spectrometer (JASCO V-670). Spectralon (Labsphere, Inc.) was used as a reference, and the powders were prepared over a quartz disc.

Elemental analysis of elements $\mathrm{C}, \mathrm{H}, \mathrm{N}$ and $\mathrm{S}$ was accomplished via high-temperature digestion coupled with dynamic gas component separation. The samples were explosively combusted at $900{ }^{\circ} \mathrm{C}$ in a highly oxygenated helium atmosphere. The combustion products were $\mathrm{CO}_{2}, \mathrm{H}_{2} \mathrm{O}, \mathrm{H}_{2}, \mathrm{NO}$, and $\mathrm{NO}_{2}$. Acetanilide was used as the standard sample for qualitycontrol measurements. The detection of the gases was performed using a thermal conductivity measurement cell. Measurements were conducted on a Flash 2000 Thermo Scientific CHNS/O analyzer.

The solid-state ${ }^{13} \mathrm{C}$ and ${ }^{29} \mathrm{Si}$ magic angle spinning nuclear magnetic resonance (MAS NMR) spectra of the PTI-0 and PTI-0.15/KCC-1 were recorded at ambient temperatures on the Bruker Avance III 400WB solid-state NMR spectrometer with an external magnetic field of 9.4T using a $4 \mathrm{~mm} \mathrm{ZrO}_{2}$ rotor with a $10 \mathrm{kHz}$ MAS spinning speed. The calibration was performed using isotopically labeled L-alanine as a standard.

X-ray Photoelectron Spectroscopy (XPS) analysis was conducted by using an AMICUS/ESCA 3400 KRATOS instrument equipped with $\mathrm{Mg}$ anodes at $12 \mathrm{kV}$ and $10 \mathrm{~mA}$. A prominent maximum peak of $\mathrm{C} 1 \mathrm{~s}$ at $284.2 \mathrm{eV}$ was taken as the reference to calibrate the XPS spectra.

Nitrogen adsorption-desorption isotherms were obtained using a Micromeritics ASAP 2420 surface area analyzer at liquid nitrogen temperature $\left(-196{ }^{\circ} \mathrm{C}\right)$. Prior to gas adsorption, all samples were degassed for $4 \mathrm{~h}$ at $120^{\circ} \mathrm{C}$.

To determine the morphology of the carbon nitride materials, field emission scanning electron microscopy (SEM) images were taken using a Nova Nano SEM instrument.

Bright-field transmission electron microscopy (TEM) and selected area electron diffraction measurements were carried out with an FEI Company's Titan 80-300 CT equipped with a field emission gun, operated at an accelerating voltage of 300 $\mathrm{kV}$. Prior to the analysis, the samples were dispersed by sonication in ethanol suspension, and the small amount of the resultant solution was dispersed on a holey-carbon film coated on a copper grid. The samples were then mounted on a doubletilt holder and transferred to the microscope. The electron energy-loss spectra (EELS) were collected in diffraction mode at an accelerating voltage of $300 \mathrm{kV}$ using a post-column filter of model GIF Tridiem from Gatan, Inc. The elemental edges of $\mathrm{C}, \mathrm{Si}$, and $\mathrm{N}$ were then analyzed to determine the elemental composition of these elements. GIF was also utilized in the energy-filtered TEM mode to show the elemental distributions of the C, Si, and $\mathrm{N}$ elements. Moreover, the C-K edge, Si-L23 edge, and $\mathrm{N}-\mathrm{K}$ edge were selected to generate the elemental maps of the $\mathrm{C}, \mathrm{Si}$, and $\mathrm{N}$ elements, respectively. The samples were also analyzed using the high-angle annular dark-field (HAADF) scanning TEM (STEM) in conjunction with energydispersive X-ray analysis (EDXA) to investigate the presence of Pt nanoparticles on the samples.

Pump-probe spectroscopy with femtosecond (fs) and broadband capabilities and $120 \mathrm{fs}$ temporal resolution was used to 
probe the dynamical events that occurred upon photoexcitation. The experimental setup is detailed elsewhere. ${ }^{43}$ Briefly stated, it employed a white light-continuum probe pulse generated in a $200 \mu \mathrm{m} \mathrm{CaF}_{2}$ crystal in an Ultrafast System LLC spectrometer using some $\mu \mathrm{J}$ pulse energy of the fundamental output of a Ti sapphire fs regenerative amplifier, operated at $800 \mathrm{~nm}$ with $40 \mathrm{fs}$ pulses and a repetition rate of $1 \mathrm{kHz}$. The pump pulses at $350 \mathrm{~nm}$ were created from fs pulses generated in an optical parametric amplifier (Newport Spectra- Physics). The pump and probe beams were finally focused on the sample, and the transmitted probe light from the excited samples and collected using broadband UV-Vis detector to record the transient absorption spectra in real time.

Photocatalytic Test. Typically, the CN catalyst $(25 \mathrm{mg})$ was dispersed in $25 \mathrm{~mL}$ of $10 \mathrm{vol} \%$ triethanolamine (TEOA) aqueous solution and then sonicated for 15-20 $\mathrm{min}$ in an ultrasonic bath. TEOA was used as a sacrificial electron donor. Then, $38.4 \mu \mathrm{L}$ of a $0.1 \mathrm{M} \mathrm{H}_{2} \mathrm{PtCl}_{6}$ solution (3 wt\% $\mathrm{Pt}$ ) was added and directly used for photocatalytic testing (photodeposition). The reactions were carried out in a Pyrex topirradiation reaction vessel connected to a glass closed gas circulation system. The reactant solutions were degassed several times to remove air. Irradiation was conducted with an Asahi Max-303 equipped with a $300 \mathrm{~W}$ Xenon lamp and a UV-Vis mirror configuration $(385-740 \mathrm{~nm})$ under an Ar atmosphere at 100 Torr. The photon flux is shown in the SI (Figure S1). The produced gases were analyzed with a gas chromatograph (Shimadzu 8A) equipped with a thermal conductivity detector with $\mathrm{Ar}$ as the carrier gas. The wavelengthdependent photocatalytic hydrogen evolution reaction (HER) for PTI-0.15/KCC-1 was conducted using an Asahi lamp with different band-pass filters, the photon distribution and numbers of which are shown in the SI (Figure S1). We confirmed that the further loading of the photocatalyst over $25 \mathrm{mg}$ in the photoreactor gave similar HER rates within experimental error.

Calculation Methods. DFT calculations were performed with the range separated hybrid functional HSE0 $6^{33}$ employing the $a b$ initio CRYSTAL14 code ${ }^{44,45}$ that uses localized (Gaussian) basis sets and self-consistently solves the Kohn-Sham equations, allowing for the efficient use of hybrid functionals. All calculations used a 6-31G(d,p) basis set, and the sampling of the Brillouin Zone was performed with a $7 \times 7 \times 3$ Monkhorst-Pack mesh ${ }^{46}$ for the bulk structures studied, assuring good convergence. To take into account dispersion interactions, the semi-empirical method proposed by Grimme, known as D2, was used. ${ }^{47}$ The dielectric constant $\varepsilon_{\mathrm{r}}$ was calculated only for bulk systems due to its cumbersome definition in two dimensions. ${ }^{48}$ Frequency calculations were performed within the harmonic approximation to the lattice potential, and infrared intensities were obtained through the Berry Phase method to determine the vibrational term $\varepsilon_{v}$ and validate the nature of the stationary points. ${ }^{49}$ The electronic term $\varepsilon_{\infty}$ was calculated with the Coupled-Perturbed Hartree-Fock (CPHF) method. ${ }^{50-52}$ Because this method is not compatible with HSE06 in CRYSTAL14, we used its parent functional PBE0 instead and for this property only. The electron affinity (EA) was computed using the protocol proposed by Stevanović et al. ${ }^{53}$ According to this protocol, the EA is obtained from the position of the conduction band (CB) of a surface of the semiconductor. A five-layer slab was used to model the surface.

\section{RESULTS AND DISCUSSION}

The synthesis procedure was established by the optimization of multiple reaction steps. ${ }^{21}$ The initial step was to select the precursor ratio of $\mathrm{Mel}$ and TAP with and without KCC-1 silica. As we reported previously, ${ }^{21}$ the supramolecular aggregation process of the $\mathrm{CN}$ precursors was found to be beneficial to improve photocatalytic performance. The process operated at $100{ }^{\circ} \mathrm{C}$ in ethanol essentially utilizes hydrogen bonding of Mel and TAP. ${ }^{21}$ The improved photocatalytic rates are likely because of the highly ordered conformation before polycondensation, leading to well-ordered crystalline polymer materials. The use of the molten salt state of the $\mathrm{LiCl} / \mathrm{KCl}$ mixture at high temperature led to crystalline polymers comprising triazine building units. ${ }^{54}$ The details of our optimization attempt at the supramolecular formation step are described in the SI (Table S1).

The copolymerization of Mel and TAP successfully tuned the bandgap. The introduction of more $\mathrm{C}$ to the aromatic ring led to narrowing the bandgap; the increase of the TAP amount in the structure, however, caused a loss of crystallinity. ${ }^{21}$ The UV-Vis spectra and XRD patterns of PTI-0, PTI-0.15 with and without KCC-1, and following silica removal are shown in Figure 1. The crystalline polytriazine imide (PTI-0 without silica) shows strong absorption in the UV range, and continues up to $\sim 460 \mathrm{~nm}$, consistent with the previous reports (Figure 1A). ${ }^{21}$ The intense peak observed at approximately $400 \mathrm{~nm}$ is assigned to a $\pi-\pi^{*}$ transition generally observed in the conjugated ring system, including the aromatic heterocycle. The peak near $500 \mathrm{~nm}$, typically assigned to the $n-\pi^{*}$ transition, which is forbidden for the strictly planar system, confirms the developed distortion in the inter-layer stacking in corroboration with the XRD pattern. ${ }^{55}$ Consistent with the previous results for the samples without silica, ${ }^{21}$ the incorporation of chemically compatible C-dopants into the PTI structure by TAP (PTI-0.15) led to a shift in the absorption edge in the visible light range up to $>600 \mathrm{~nm}$ (Figure 1A). This increase in C-dopants also led to loss of crystallinity (Figure 1B) and the further incorporation of TAP leads to produce amorphous nature of the materials. ${ }^{21}$ In the presence of KCC- 1 slight hypsochromic shifts of the absorption edges were observed compared to those without KCC-1. Silica removal through treatment with aq. $\mathrm{NH}_{4} \mathrm{HF}_{2}$ caused a further hypsochromic shift.

Elemental analyses showed that the $\mathrm{C} / \mathrm{N}$ molar ratio rose with the increase in dopant concentration (Table 1). Typically, the $\mathrm{C} / \mathrm{N}$ ratio was 0.66 for $\mathrm{PTI}-0$, whereas it increased to 0.76 for PTI-0.15. The presence of KCC-1 did not alter the $\mathrm{C} / \mathrm{N}$ ratio significantly $(0.78$ for PTI- $0.15 / \mathrm{KCC}-1)$. The powder XRD patterns of PTI-0 showed sharper crystalline peaks, reflecting a better crystalline structure (Figure 1B). Previously, we demonstrated that the simultaneous decrease in the bandgap as well as crystallinity of the materials upon increasing the TAP amount. ${ }^{21}$ The incorporation of the TAP unit in the PTI polymer (PTI-0.15) reduced the degree of crystallinity compared to that of PTI-0 (Figure 1B). The peak appeared at $12.2^{\circ}$ ( $2 \theta$ value) was attributed to the in-plane arrangement of the triazine building units. The presence of silica (PTI$0.15 / \mathrm{KCC}-1)$ does not affect the XRD pattern significantly. Moreover, the contraction of the interlayer spacing $\left(\mathrm{d}_{002}\right)$ from $3.25 \AA$ to $3.17 \AA$ indicated the $\mathrm{CN}$ layer distance decreased upon removal of the silica template (Figure 1B), consistent with the literature. ${ }^{56}$ 
Table 1. CHN elemental analysis results and surface area of the synthesized PTI samples.

\begin{tabular}{llllllll}
\hline Sample & $\begin{array}{l}\text { Mel:TAP } \\
{[\text { mol ratio }]}\end{array}$ & $\begin{array}{l}\mathrm{C} \\
{[\mathrm{wt} \%]}\end{array}$ & $\begin{array}{l}\mathrm{N} \\
{[\mathrm{wt} \%]}\end{array}$ & $\begin{array}{l}\mathrm{H} \\
{[\mathrm{wt} \%]}\end{array}$ & $\mathrm{C} / \mathrm{N} / \mathrm{H}$ & $\begin{array}{l}\mathrm{C} / \mathrm{N} \\
\text { mol ratio }\end{array}$ & $\begin{array}{l}\text { BET surface area } \\
{\left[\mathrm{m}^{2} \mathrm{~g}^{-1}\right]}\end{array}$ \\
\hline PTI-0 & $1: 0$ & 28.1 & 49.4 & 1.8 & $\mathrm{C}_{3.0} \mathrm{~N}_{4.5} \mathrm{H}_{2.3}$ & 0.66 & 90 \\
PTI-0.15 & $1: 0.15$ & 27.1 & 41.8 & 2.5 & $\mathrm{C}_{3.1} \mathrm{~N}_{4.1} \mathrm{H}_{3.4}$ & 0.76 & 178 \\
PTI-0.15/KCC-1 & $1: 0.15$ & 27.0 & 40.5 & 2.5 & $\mathrm{C}_{3.2} \mathrm{~N}_{4.1} \mathrm{H}_{3.6}$ & 0.78 & 177 \\
PTI-0.15/KCC-1 silica removal & $1: 0.15$ & 29.8 & 45.8 & 3.1 & $\mathrm{C}_{3.1} \mathrm{~N}_{4.1} \mathrm{H}_{3.8}$ & 0.76 & 125 \\
\hline
\end{tabular}

${ }^{\mathrm{a}} \mathrm{KCC}-1$ silica was not used for the synthesis.
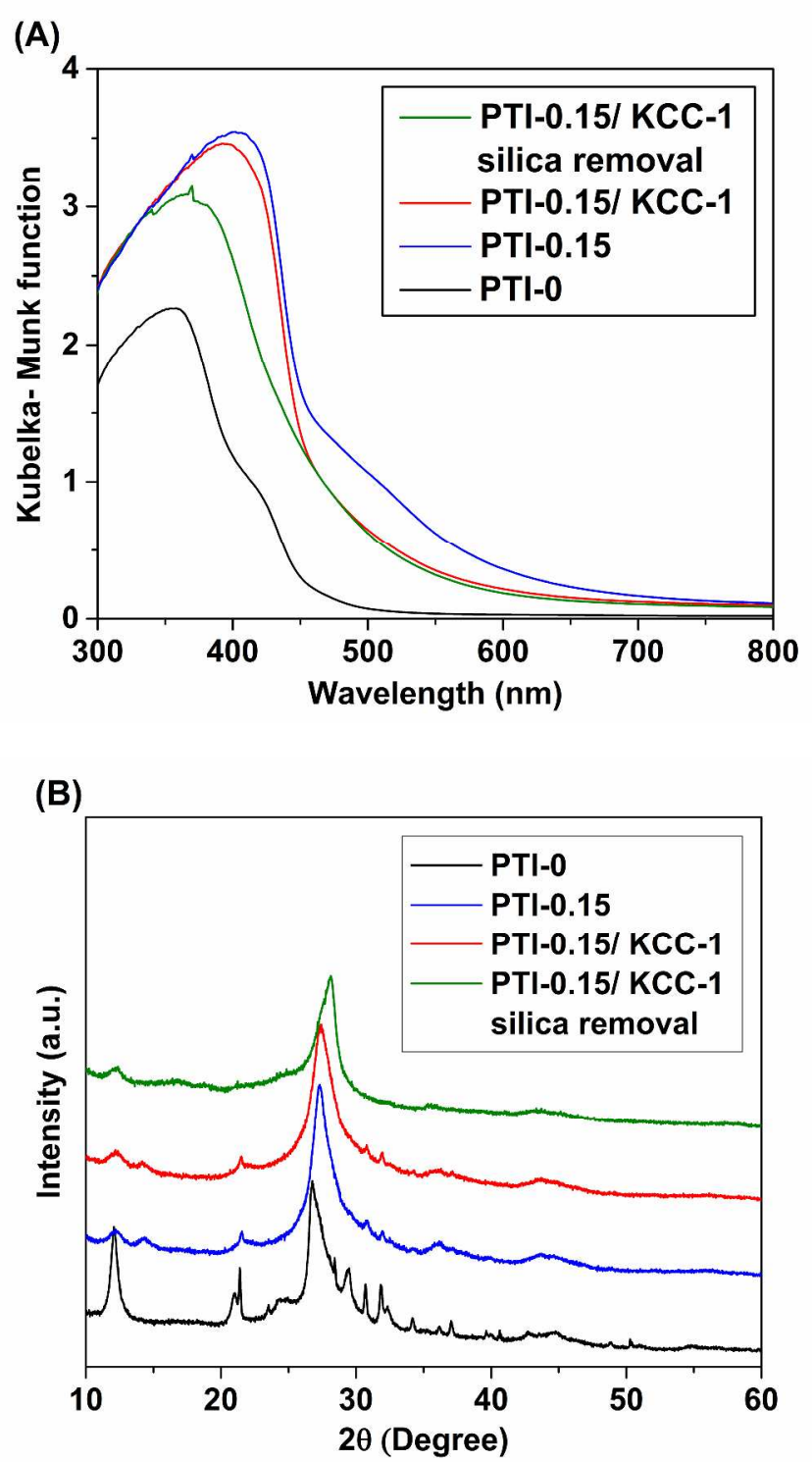

Figure 1. (A) Diffuse reflectance UV-Vis spectra and (B) XRD patterns for the PTI samples.

DFT calculations were used to describe the copolymerization effects on the structure and optical properties. The $\mathrm{CN}$ was modeled by the incompletely polymerized PTI- 0 structure proposed by Lotsch and coworkers, ${ }^{57}$ from which $\mathrm{LiCl}$ was removed, thus leading to the composition $g-\mathrm{C}_{6} \mathrm{~N}_{9} \mathrm{H}_{3}$. Refining the $\mathrm{P}_{3} \mathrm{~cm}$ structure proposed in the literature yielded a local minimum with $\mathrm{P}_{3} / \mathrm{mcm}$ symmetry. The chemical and $3 \mathrm{D}$ structures of all the compounds are provided in Figure 2. For PTI-0 (Figure 2D), it can be seen that the rings are superimposed along the interlayer direction, probably to favor the $\pi$ stacking while the atoms from one layer to another are not aligned to avoid steric repulsion. The computed bandgaps are presented in Table 2. For the PTI-0 bulk system, the bandgap corresponding to the energy difference between the top of the valence band and the bottom of the conduction band (noted $E_{g}^{e l}$ ) was found to be $4.37 \mathrm{eV}$. But this property does not correspond to the optical bandgap measured experimentally. The optical bandgap (noted $E_{g}^{\text {opt }}$ ) is obtained by reducing the value of $E_{g}^{e l}$ by the binding energy of exciton. In standard semiconductors, the binding energy of exciton is relatively small leading to a similar value for $E_{g}^{\text {el }}$ and $E_{g}^{\text {opt }}$. But for $\mathrm{CN}$ materials, this is different. The binding energy of exciton is higher than $1 \mathrm{eV}$ leading to computed optical bandgap around $3.0 \mathrm{eV}$ closer to experimental value $(\sim 2.6 \mathrm{eV}) .{ }^{13}$ The slight discrepancy between DFT and experiment for the optical bandgap could remain in the structure of the $\mathrm{CN}$ that is perfectly polymerized and crystallized in the DFT calculation while it is not perfectly crystallized experimentally.

The influence of C-doping by TAP was investigated only on monolayers because no resolved structures were obtained for this type of doping. C-doping concentrations of $0,12.5$ and $50 \%$ were investigated, which correspond to PTI-0, PTI-0.143, and PTI-1, respectively. The optimized structures of the doped systems are visualized in Figure 2A-C. The influence of the monolayer approximation on the bandgap was first investigated on PTI-0. The calculations revealed a $0.48 \mathrm{eV}$ increase in bandgap upon exfoliation to the monolayer, consistent with the trend of the measured values. ${ }^{58}$ Following a single point calculation on one non-optimized layer in the bulk structure, it was determined that this effect is almost entirely electronic and unrelated to the relaxation of the atomic positions. Five layers of PTI-0 led to a bandgap of $4.4 \mathrm{eV}$, sufficient to represent that of the bulk material, confirming the influence of the packing to narrow the corresponding bandgap. ${ }^{58}$

Figure 3 presents the band positions for the five-layer slab of PTI-0 and TAP-doped PTI monolayers. Using a monolayer configuration, the calculation revealed a bandgap reduction by $0.6 \mathrm{eV}$ by PTI-0.143 with respect to PTI- 0 . This bandgap reduction came from a negative shift in the valence band (VB) level upon doping, an effect known to occur upon atomic substitution by a less electronegative element, ${ }^{59,60}$ and con- 
Table 2. Computed semiconductor properties at the HSE06 level for the PTI samples.

\begin{tabular}{|c|c|c|c|c|c|c|c|}
\hline \multirow[t]{2}{*}{ Material } & \multirow{2}{*}{$\begin{array}{l}\text { Bandgap } \\
\text { nature }\end{array}$} & \multirow{2}{*}{$\begin{array}{c}\text { Electronic } \\
\text { Bandgap } \\
E_{g}^{\mathrm{el}}(\mathrm{eV})\end{array}$} & \multirow{2}{*}{$\begin{array}{l}\text { Optical } \\
\text { Bandgap } \\
E_{g}^{\text {opt }}(\mathrm{eV})\end{array}$} & \multirow{2}{*}{$\begin{array}{c}\text { Dielectric } \\
\text { constant }^{\mathrm{a}} \\
\varepsilon_{\mathrm{r}}\end{array}$} & \multirow{2}{*}{$\begin{array}{c}\text { Exciton binding } \\
\text { energy } \\
E_{\mathrm{b}}(\mathrm{eV})\end{array}$} & \multicolumn{2}{|c|}{ Effective mass } \\
\hline & & & & & & $m_{\mathrm{e}}$ & $m_{\mathrm{h}}$ \\
\hline PTI-0 (Bulk) & $\mathrm{K} \rightarrow \mathrm{K}$ & 4.37 & 3.02 & 4.6 & 1.35 & 0.7 & 1.9 \\
\hline PTI-0 (ML) ${ }^{\mathrm{b}}$ & $\Gamma \rightarrow \Gamma$ & 4.85 & 3.81 & $(4.6)$ & 1.04 & 0.5 & 1.9 \\
\hline PTI-0.143 (ML) ${ }^{\mathrm{b}}$ & $\Gamma \rightarrow \Gamma$ & 4.22 & 3.04 & $(4.6)$ & 1.18 & 0.5 & 2.5 \\
\hline PTI-1 (ML) ${ }^{\mathrm{b}}$ & $\Gamma \rightarrow \Gamma$ & 4.19 & 2.99 & $(4.6)$ & 1.20 & 0.5 & 2.6 \\
\hline
\end{tabular}

${ }^{a}$ Bulk dielectric constants were used for the monolayers (presented in italic).

${ }^{\mathrm{b}} \mathrm{ML}$ means monolayer.

reveals that the first transition is direct and occurs at the Kpoint and further reveals a degree of electron mobility in the molecular plane, as shown by the curvature of the Conduction Band in the K-M and K- $\Gamma$ directions. A shift as observed here, from a K-point to a $\Gamma$-point transition, is common upon going from a bulk to a $2 \mathrm{D}$-material. ${ }^{61}$ The path corresponding to interlayer crossing, $\Gamma$-A, expectantly reveals that charge mobility in the interlayer direction is negligible. The DOS reveals that, as shown in Figure 4B, the $\mathrm{N}$ atoms are the main contributors to the VB on pure PTI- 0 , and a modification made onthis position (such as $C$ substitution) will strongly affect the VB edge energy. The CB consists of an anti-bonding combination of $\mathrm{C}$ and $\mathrm{N} 2 \mathrm{p}$ orbitals and is affected negligibly by substitution on the $\mathrm{N}$ site. The conduction band also exhibits a negative shift upon doping by TAP, but it is less pronounced than the valence band, leading to bandgap reduction. Notably, the further increase in doping amount from $12.5 \%$ to $50 \%$ did not significantly alter the VB and CB positions, leading to a similar bandgap for the two doping concentrations. For a bandgapengineering point of view, only a slight doping is needed. Nevertheless, this negative shift of valence band of $0.6 \mathrm{eV}$ still allows the oxygen evolution reaction to happen thermodynamically (See Figure 3).

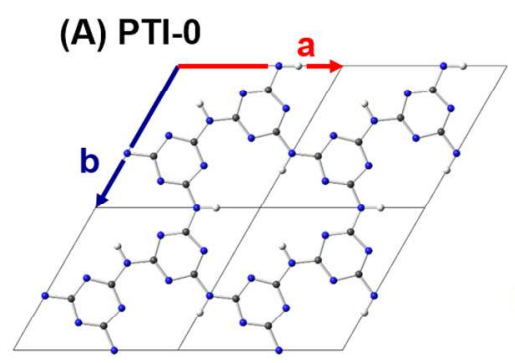

(B) PTI-0.143

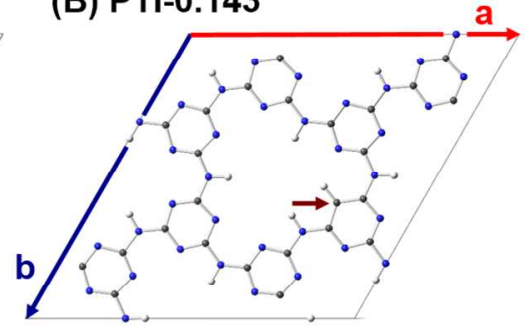

(C) PTI-1

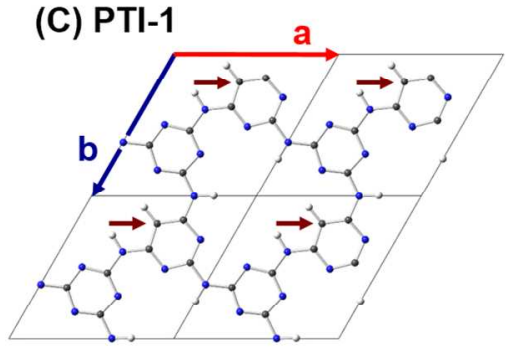

(D) PTI-0 3D view

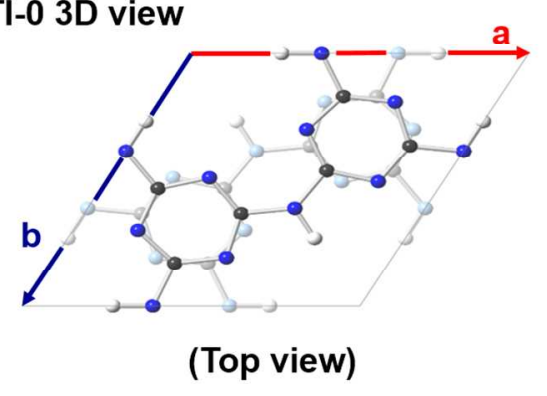

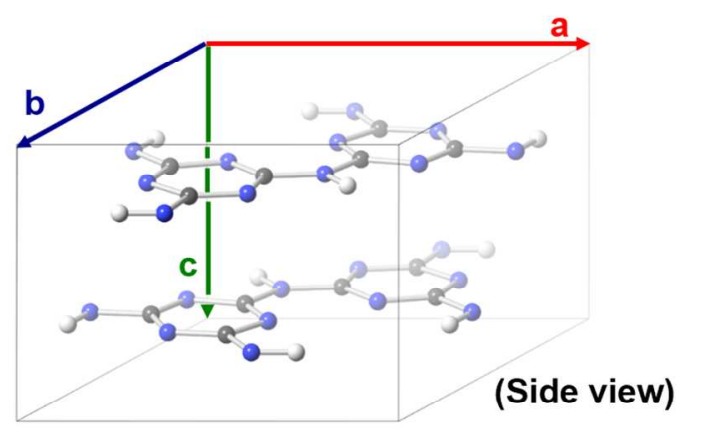

(E) PTI TAP steric repulsion

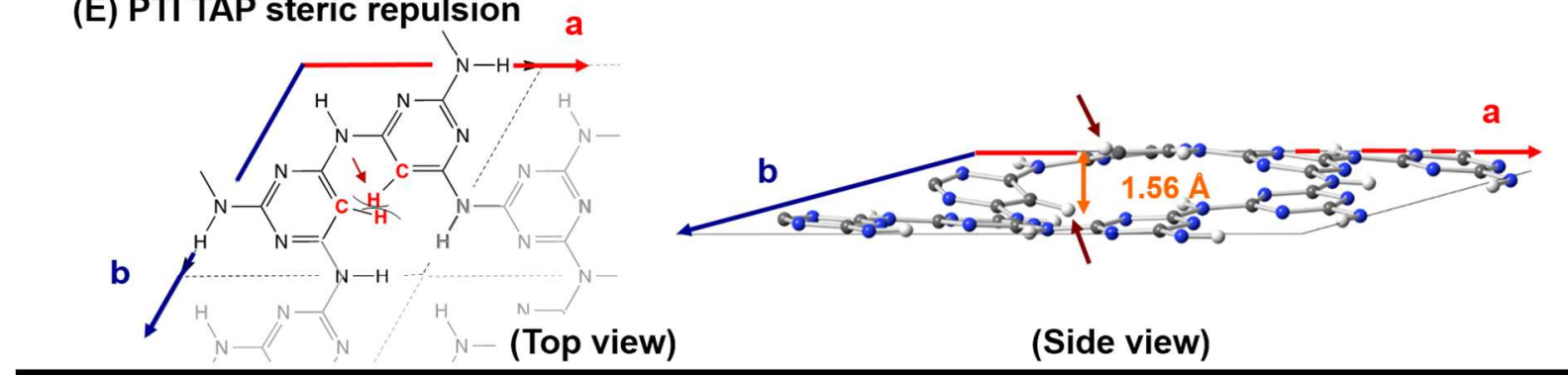


Figure 2. Schematics of optimized structures by DFT.

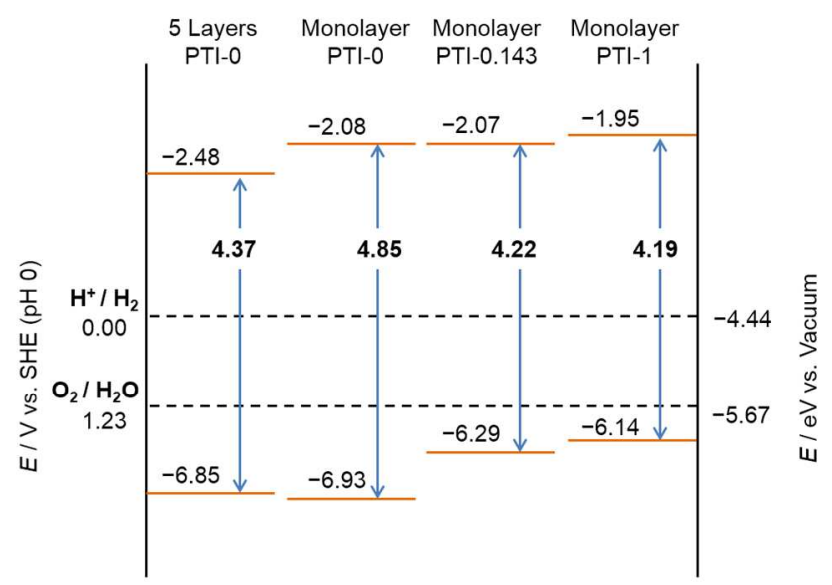

Figure 3. Bandgap energies and band positions calculated by DFT.

DFT geometries predicted an interlayer distance of $3.26 \AA$ of the bulk PTI-0 system, in good agreement with the experimentally obtained values $(\sim 3.2 \AA)$. In a planar dimension, a dihedral angle of $0^{\circ}$ was calculated. When two neighboring molecules are both TAP molecules, as shown in Figure 2E, the dihedral angle between the repulsive groups is $21.7^{\circ}$, and the resulting corrugation of an individual layer was found to be $1.56 \AA$, explaining the loss of crystallinity upon increasing the TAP content observed in the XRD patterns (Figure 1B). The energy of stabilization involved by the torsion of the layer when two TAP molecules are adjacent is computed to be $26 \mathrm{~kJ}$ $\mathrm{mol}^{-1}$, compared to a situation where the two adjacent TAP molecules are coplanar.

The morphological characterizations of the synthesized CNs were conducted by field emission SEM, and the results are shown in Figure 5. Typical synthesis of PTI structure without silica leads to a thick, rod-like morphology with the diameter of 0.5-2 $\mu \mathrm{m}$, with smaller hairy rod-like shapes (a few tens of $\mathrm{nm}$ ) that are grown outwards (Figure 5a). In contrast, synthesis of $\mathrm{CN}$ on KCC-1 fiber (PTI-0.15/KCC-1) resulted in CN fibers with a thickness of 20-30 nm, projected outwards of the sphere and assembled in an organized way (Figure 5c), re flecting the uniformly sized nano-sphere with dendritic fiber oriented three dimensionally with a diameter of 300 to $500 \mathrm{~nm}$ for the pristine $\mathrm{KCC}-1$ (Figure 5b). A hollow, spherical $\mathrm{CN}$ was likely formed after the removal of the silica template (Figure 5d), implicating the efficient use of a hard template for nano- or micro-structuring. In addition to spherical dendritic $\mathrm{CN}$, a hedgehog-like morphology was also observed.
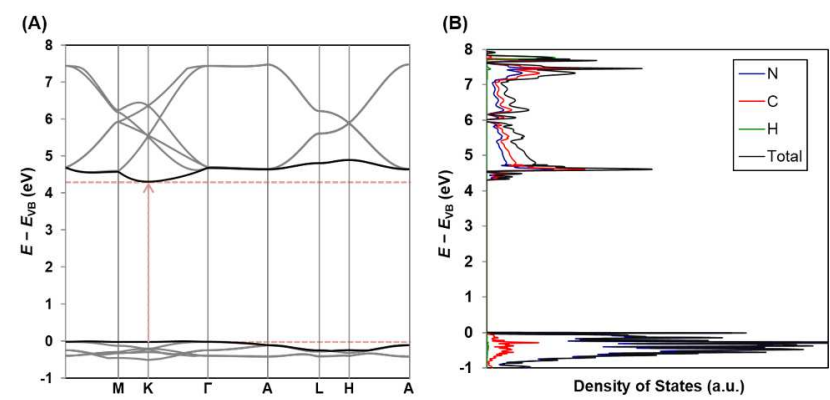

Figure 4. (A) Band structure and (B) DOS for PTI-0 five layers.
The microstructure of $\mathrm{CN}$ was further analyzed by a brightfield TEM, as shown in Figure 6. A spherical morphology with sharp CN fibers was observed for the PTI-0.15/KCC-1 sample. To understand the composition of the sample, we performed EELS, which demonstrates the presence of the $\pi$ conjugated $\mathrm{C}-\mathrm{N}$ bond together with the presence of $\mathrm{Si}$ in the PTI-0.15/KCC-1 structure. To ensure the exact position of silica, we also performed $\mathrm{C}, \mathrm{N}$, and $\mathrm{Si}$ elemental mapping with energy-filtered TEM (EFTEM) technique, which confirmed the spherical growth of $\mathrm{CN}$, reflecting the original morphology of KCC-1. It appears that KCC-1 lost its original shape and the resultant $\mathrm{CN}$ looks hollow structure. To investigate any change in the silica structure, we heated KCC-1 with the same amount of salt mixture without using $\mathrm{CN}$ precursors. After washing the excess salt with hot water, we found the KCC-1 with a hollow structure (Figure S2). Heating KCC-1 itself at $550{ }^{\circ} \mathrm{C}$ showed only the reduced thickness of the fiber from 10 to $5 \mathrm{~nm}$ and showed that the fibrous structure was stable up to $950{ }^{\circ} \mathrm{C} ;{ }^{39}$ therefore, the salt mixture (alkali ions) at high temperature indeed reacted with silica, thus collapsing the fibrous nature and rendering it hollow instead. It is considered that the dendritic morphology of the $\mathrm{CN}$ is determined relatively at lower temperatures, utilizing original morphology of silica, and then at higher temperature, where $\mathrm{CN}$ polymerization in molten salt state happens, simultaneous removal and distortion of its original macroscopic morphology happens to create hollow CN structure.

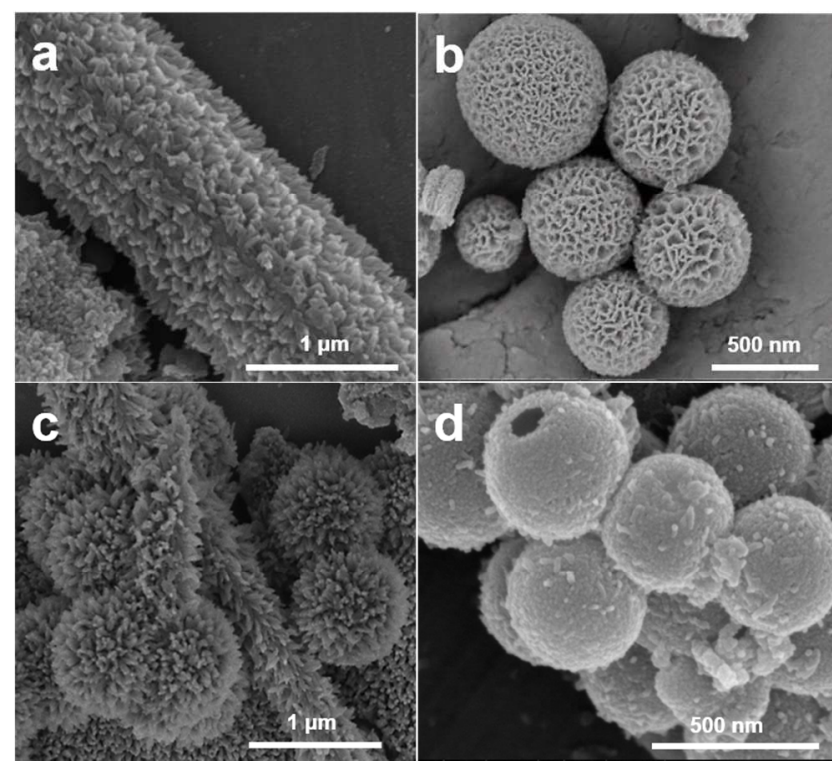

Figure 5. SEM images of (a) PTI-0.15, (b) KCC-1, (c) PTI0.15/KCC-1, and (d) PTI-0.15/KCC-1 after silica removal.

In the IR spectra, absorption bands at 1271 and $1370 \mathrm{~cm}^{-1}$ were found in the PTI-0 structure. They were assigned to be characteristic of the C-NH-C unit (Figure S3). With the addition of TAP, a new peak was observed at $910 \mathrm{~cm}^{-1}$ in PTI- 0.15 samples. This peak is typically attributed to the out-of-plane bending vibration of aromatic $\mathrm{C}-\mathrm{H}$, consistent with the successful incorporation of pyrimidine into the $\mathrm{CN}$ structure. The peaks appeared at 1460 and $1581 \mathrm{~cm}^{-1}$ were the vibrational mode specific to the ring deformation. The characteristic peak for triazine ring breathing appeared at $806 \mathrm{~cm}^{-1}$ for all samples. Thus, the IR and elemental analysis results clearly indi- 
cate the incorporation of $\mathrm{C}$ atoms through the integration of the pyrimidine moiety into the $\mathrm{CN}$ network.
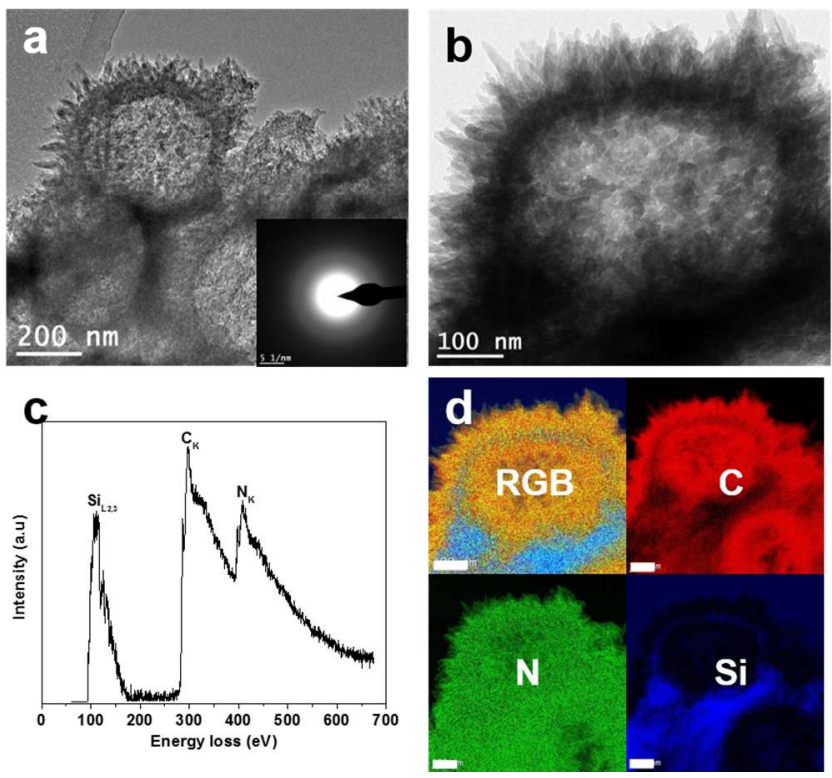

Figure 6. (a) Bright-field TEM of the PTI- $0.15 / \mathrm{KCC}-1$, (b) Bright-field TEM, (c) an EELS spectrum acquired from the spherical CN shown in (b), and (d) elemental mapping where red, green and blue correspond to $\mathrm{C}, \mathrm{N}$ and $\mathrm{Si}$, respectively, and RGB shows total (white bar: $100 \mathrm{~nm}$ ).

Solid-state magic-angle-spinning (MAS) NMR spectra provide useful information about the structural insight of the $\mathrm{CN}$ backbone. Because the PTI-0.15/KCC-1 contains comparatively less silica, we performed single pulse ${ }^{29} \mathrm{Si}$ MAS NMR spectroscopy, and the resulting spectrum showed one characteristic signal at $\delta=-119 \mathrm{ppm}$ (Figure S4), which was slightly lower than the value ( $\delta=-109 \mathrm{ppm})$ generally assigned to the Q4 sites corresponding to the $\mathrm{SiO}_{4}$ substructures, observed in KCC-1. Unlike these latter two, the spectra of PTI-0.15/KCC1 contained no peak attributed to Q3 and Q2 sites at $\delta=-100$ and $-91 \mathrm{ppm}$, meaning that the amount of free silanol groups was too small to be detectable. As seen in Figure S4, a very strong signal was observed at $\delta \approx 162 \mathrm{ppm}$ in the ${ }^{13} \mathrm{C}$ cross polarization MAS NMR spectrum of PTI- $0.15 / \mathrm{KCC}-1$, attributed to the characteristic peak of the ring carbon of the triazine or heptazine moiety.

We also performed XPS analysis of the three samples, PTI0.15 , PTI-0.15/KCC-1 and PTI-0.15/KCC- 1 silica removal (Figures S5-S7). For the PTI-0.15/KCC-1 sample, the survey scan spectrum confirmed the presence of carbon, nitrogen, oxygen and silicon. From the deconvoluted $\mathrm{C} 1 \mathrm{~s}$ spectrum, two major peaks were identified, one at $287.5 \mathrm{eV}$ attributed to $\mathrm{sp}^{2}$-bonded carbon $(\mathrm{C}=\mathrm{N})$ and another at $284.9 \mathrm{eV}$ assigned to graphitic carbon. The $\mathrm{N} 1 \mathrm{~s}$ spectrum was deconvoluted into four peaks with binding energies at 398.3, 399.9, 401.0 and $403.5 \mathrm{eV}$, where the highest intensity peak at $398.3 \mathrm{eV}$ was assigned to $\mathrm{sp}^{2}$-bonded nitrogen $(\mathrm{N}=\mathrm{C})$ within an aromatic ring, and the peak at 399.9 attributed to $\mathrm{sp}^{3}$ nitrogen or bridging nitrogen. ${ }^{20}$ The observed separation in binding energy between N-ring and N-bridging was $1.6 \mathrm{eV}$. A clear Si 2p XPS peak with binding energy of $103.8 \mathrm{eV}$ confirmed the presence of silicon in PTI-0.15/KCC-1, whereas, other two samples did not show any peak related to silicon.
The surface area for KCC-1 was $368 \mathrm{~m}^{2} \mathrm{~g}^{-1}$ (Table 2), and isotherm showed a type-IV of typical mesoporous materials (Figure S8). The surface areas of PTI-0, PTI-0.15 and PTI$0.15 / \mathrm{KCC}-1$ were 90,178 , and $177 \mathrm{~m}^{2} \mathrm{~g}^{-1}$, respectively. A very similar surface area as well as pore size and volume (Table S2) were observed for the sample with and without using the KCC-1 template, not accounting for any differences in photocatalytic activity. Silica removal with aq. $\mathrm{NH}_{4} \mathrm{HF}_{2}$ led to a decrease in surface area, consistent with the destruction of the fibrous morphology observed in the SEM image (Figure 5d). The BET surface area of PTI-0.15 was found to be larger than that of PTI-0 because of its relatively amorphous structure caused by the TAP doping, consistent with the XRD pattern (Figure 1B).

To further understand the applicability of $\mathrm{CN}$ in photocatalytic water splitting, we invoked further our DFT approach to compute several fundamental properties, such as the dielectric constant, $\varepsilon_{r}$, that influence the exciton binding energy $\left(E_{b}\right)$, the effective mass, $m^{*}$, and the charge carrier's mobility $\mu$ (Table 1)..$^{34,62,63}$ A detailed explanation of how these properties are calculated is available in the literature. ${ }^{34}$ It should be reiterated that the exciton binding energy is computed in the framework of the Wannier-Mott model. More precisely, the 2D WannierMott exciton was used (see supporting information for equations).$^{64}$ The dielectric constant of bulk PTI-0 is equal to 4.6, lying between the values typically obtained for inorganic semiconductors $(>10)$ and polymeric semiconductors $(\sim 3){ }^{65}$
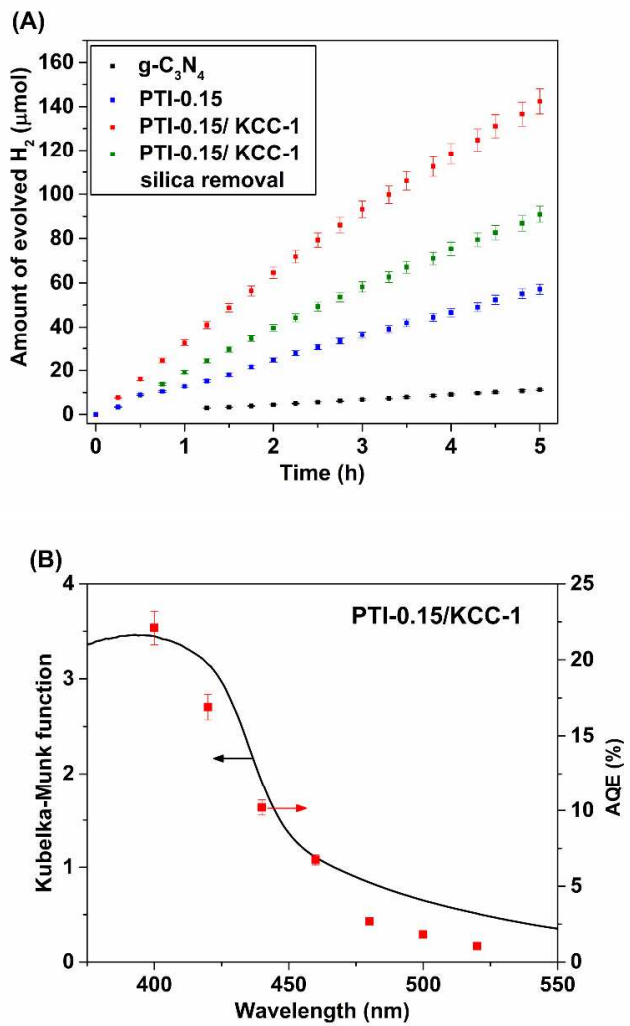

Figure 7. (A) Time course of the amount of hydrogen evolved for photocatalytic HER, and (B) action spectra for photocatalytic HER compared with Kubelka-Munk function for PTI-0.15/KCC-1 (300 W Xe-lamp with $385-740 \mathrm{~nm}$ or using band-pass filters, $25 \mathrm{mg}, 3 \mathrm{wt} \% \mathrm{Pt}$ photodeposition, 10 vol \% TEOA/water solution). 
The band structure and DOS for the bulk system are supplied in Figure 4. For the charge-carrier mobilities, the electron appears relatively well delocalized, with effective masses of approximately $0.5 m_{\mathrm{e}}$, whereas the holes are much more localized, with $\sim 2 m_{\mathrm{e}}$. This difference in effective mass is a common phenomenon in standard semiconductors. Nevertheless, because of the low dielectric constant and the layered structure, $E_{b}(1.03 \mathrm{eV}$ for the monolayer of PTI-0, see Table 1) is much higher than the thermal energy. The computed values of $E_{b}$ within the Wannier-Mott model give values very similar to those obtained by the $\mathrm{G}_{0} \mathrm{~W}_{0}$ - $\mathrm{BSE}$ approach on pure $g-\mathrm{C}_{3} \mathrm{~N}_{4}$ invoked by Wei et al., confirming the choice of the 2D Wannier-Mott model. ${ }^{66}$ Due to the high $E_{b}$, the photogenerated exciton is not spontaneously dissociated at room temperature, thereby increasing the probability of recombination. Effective utilization of the interface with the cocatalyst is therefore required to achieve high photocatalytic efficiency. No decrease in $E_{b}$ is found upon increasing the doping level from 12.5 to $50 \%$. This confirms that a small amount of doping lowers bandgap without distorting the material structure; a larger amount of doping does not improve the excitonic properties but distorts the structure. Consistent with this calculation, a high ratio of the TAP molecule experimentally led to the destruction of crystallinity of PTI structure. Therefore, in this study, we focused on the PTI-0.143 (DFT) and PTI-0.15 (experiment), where the crystalline nature remains, and bandgap narrowing is prevalent.

Initially, the sample without KCC-1, PTI-0.15, was tested for the photocatalytic HER rate using $3 \mathrm{wt} \% \mathrm{Pt}$ as a cocatalyst in 10 vol\% aqueous TEOA solution $(\mathrm{pH}=10.8)$ using an Asahi Xe lamp with a 385-740 nm cut-off filter; the HER was $13 \mu \mathrm{mol} \mathrm{h}^{-1}$, which was a factor of 6 times faster than that of the $g-\mathrm{C}_{3} \mathrm{~N}_{4}$ reference (Figure 7A). When the KCC-1 was used as a removable template, after silica leaching from the $\mathrm{CN}$, the hollow spherical PTI-0.15 showed a slight increase in the $\mathrm{HER}, 20 \mu \mathrm{mol} \mathrm{h}^{-1}$. Intriguingly, the highest activity seen in the CN sample with KCC-1, PTI-0.15/KCC-1 was $33 \mu \mathrm{mol} \mathrm{h}^{-1}$, which is almost 17 times higher than that of $g-\mathrm{C}_{3} \mathrm{~N}_{4}$. It seems reasonable to assume that surface reconstruction also occurs in the materials during silica removal and that this could be responsible for the loss of activity $\left(20 \mu \mathrm{mol} \mathrm{h} \mathrm{h}^{-1}\right)$. Beside the effect on the semiconductor's morphology when covering the silica with $\mathrm{CN}$, the effect of the mere presence of silica nanoparticles on the CN's photocatalytic activity was investigated in physical mixing. Benefits of the physical mixture, such as the possible increase in the path length of the incoming light through Mie scattering by the nanoparticles, could be identified in this manner. However, no improvement was found. A close interconnection and proper arrangement of the resultant $\mathrm{CN}$ from the use of silica might be needed for higher activity. Additionally, the sample without TAP, PTI-0/KCC-1 showed inferior photocatalytic activity (no detectable $\mathrm{H}_{2}$ ), suggesting that the effect of TAP is prevalent on the photon absorption and the resultant photocatalytic activity rather than that of silica. The stability of the PTI-0.15/KCC-1 was tested by performing the photocatalytic reaction for several cycles (Figure S10). Deactivation was observed after first run (10 h) but after that it showed stable performance for another $40 \mathrm{~h}$ of reaction.

In general, time-resolved laser spectroscopy is an extremely powerful technique to probe various recombination mechanisms and their dynamics. ${ }^{67-70}$ Because the dynamics of ground-state bleach recovery are directly proportional to the exciton depopulation, they are used as a convenient probe to determine the excited state dynamics including electron trapping and charge separation and recombination at materials surfaces and interfaces. After $350 \mathrm{~nm}$ of optical excitation, which was above the bandgap excitation, a clear ground-state bleach of approximately $500 \mathrm{~nm}$ corresponding to steady-state absorption was observed for the materials with a slight change in spectral features, as shown in Figure S9. By analyzing the dynamics of the transient signal using a global-fitting procedure (Table S3), we observed that each decay curve in the fsps regime (Figure 8) had a fast component with a characteristic time constant of a few picoseconds and a slow component with a time constant of hundreds of picoseconds. More specifically, we show that carrier recombination of PTI-0.15/KCC-1 became slower compared to PTI-0.15/KCC-1 after silica removal and PTI-0.15. In other words, our results clearly demonstrate a significantly slower carrier recombination for $\mathrm{CN}$ with silica than the others. Such long lifetimes of excited carriers in the presence of silica can be directly correlated with the high photocatalytic activities reported in this study.

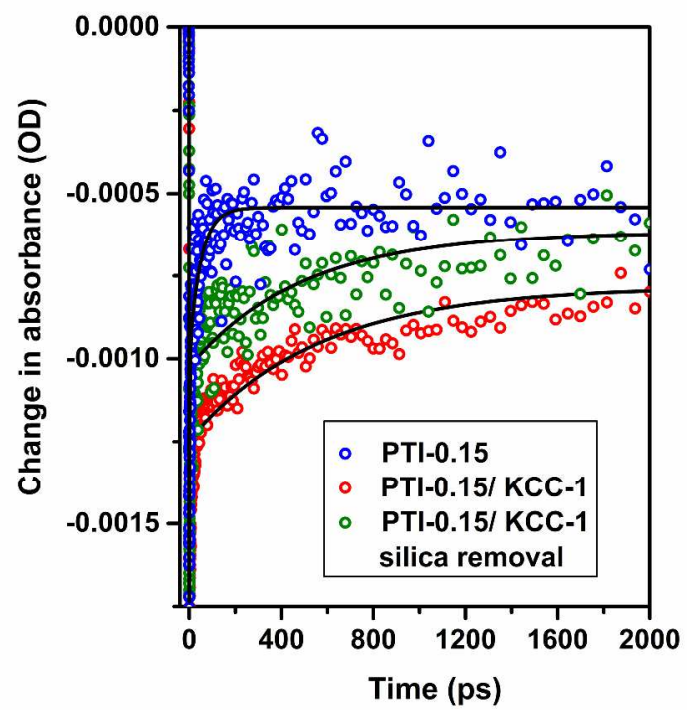

Figure 8 . Kinetics traces at the center of the corresponding ground state bleach for PTI-0.15, PTI-0.15/ KCC-1 and PTI-0.15/ KCC-1 after silica removal $\left(\lambda_{\mathrm{exc}}=350 \mathrm{~nm}\right)$ in fs-ps regime.

To determine exactly which wavelength contributed to the HER, action spectra of PTI-0.15/KCC-1 were measured after $15 \mathrm{~h}$ reaction using different band-pass filters. As shown in Figure $7 \mathrm{~b}$, the AQE of the PTI-0.15/KCC- 1 for HER at 400 and $420 \mathrm{~nm}$ was as high as $22.1 \%$ and $16.9 \%$, respectively, which are among the highest efficiencies reported using $\mathrm{CN}$ photocatalysts. Trend of photocatalytic activity as a function of excitation wavelength follows that of absorption spectrum of the material. Noticeably, the extended visible-light absorption truly contributed to the photocatalytic HER, though there was a little decrease in activity. This decreased photocatalytic efficiency in the extended visible-light range can likely be explained in terms of a weak absorption coefficient (n to $\pi^{*}$ excitation) and the localized electronic states that developed from the presence of dopant.

HAADF-STEM analysis showed that the spherical morphology after $15 \mathrm{~h}$ of photocatalytic reaction (Figure 9a) was retained. The growth of carbon nitride nanofiber was regularly assembled surrounding the sphere and after reaction this as- 
sembly was found to be largely intact with some slight deformation. Highly dispersed, very small Pt nanoparticles were found (Figure 9c) and confirmed by EDXA (Figure 9d), in addition to some relatively large particles of an average diameter of $\sim 4.2 \mathrm{~nm}$ (Figure 9b), indicating a possible reason for the high activity of this material. The powder XRD of the PTI-0.15/KCC-1 after a photocatalytic reaction (Figure S11) revealed the preserved pattern, indicating its structural robustness.
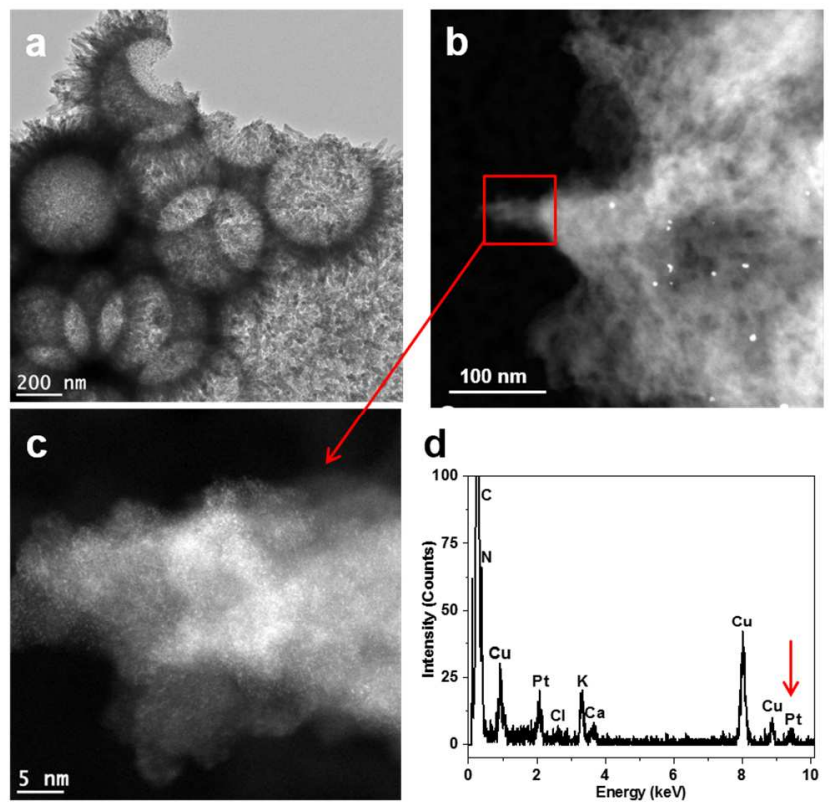

Figure 9. Bright-field TEM image of PTI-0.15/ KCC-1 after $15 \mathrm{~h}$ of photocatalytic reaction. (b) HAADF-STEM image of highly dispersed $\mathrm{Pt}$ nanoparticles ( $c a .4 \mathrm{~nm}$ ) on the carbon nitride. (c) Magnified portion showing very small Pt nanoparticles. (d) An EDS spectrum from the magnified portion confirming the presence of Pt.

As discussed previously, the DFT calculations (Table 1) highlight that large exciton binding energy is the bottleneck for the use of $\mathrm{CN}$ in photocatalysis. ${ }^{71}$ From that point of view, $\mathrm{CN}$ can be seen as very similar to semiconductor polymers such as poly 3-hexylthiophene (P3HT), the exciton diffusion length of which was reported to be approximately $10 \mathrm{~nm}^{72,73}$ To overcome this exciton dissociation problem in polymer photovoltaics, the community developed the so-called bulkheterojunction architecture. ${ }^{74}$ This bulk-heterojunction effectively utilizes the interface between the electron- and holeconducting material mixed at molecular level, increasing the probability for the exciton to encounter an interface prior to recombination. Based on the results presented in this paper, it is concluded that the same architecture is necessary for $\mathrm{CN}$ based photocatalytic devices. Our $\mathrm{CN}$ forms fiber-like morphology of $\sim 30 \mathrm{~nm}$ width. Due to the similarities of $\mathrm{CN}$ with polymer semiconductor, it can be assumed that the diffusion length of the exciton is around $50 \mathrm{~nm}$. This means that the exciton must encounter an interface within $\sim 50 \mathrm{~nm}$ to be dissociated. Using a large surface area of the $\mathrm{CN}$, a large dispersion of Pt clusters will create effective junction at metalsemiconductor interface, helping to dissociate exciton due to the energy difference between the $\mathrm{CB}$ of $\mathrm{CN}$ and the Fermi energy of Pt. In contrast to classical bulk heterojunction, the full surface of $\mathrm{CN}$ should not be covered by the cocatalyst because the hole (which remains inside the $\mathrm{CN}$ after the dissociation) must react with the hole scavenger at the interface between $\mathrm{CN}$ and the electrolyte. The presence of this silica might help scavenge the surface holes ${ }^{75}$ and thereby, surface electrons can have time to go to the Pt active site, precluding the loss due to electron-hole recombination, which is prevalent in bare $\mathrm{CN}$. Thus, the competitive process of trapping the charge carrier, particularly the hole, by the existing defects in the silica in a way hinders the recombination loss and enhances the photocatalytic activity by promoting electron-hole separation. In general, for the HER, the rate of the hole transfer from the heterostructure is the limiting factor, as supported by our DFT calculations that give high effective masses for holes. Thus, here, thin $\mathrm{CN}$ nanofibers together with very small $\mathrm{Pt}$ nanoparticles have a profound effect on fast charge collection, and thereby reduce recombination and increase HER rates.

\section{CONCLUSIONS}

The PTI-based CN photocatalyst with various carbon to nitrogen ratio provided a tunable bandgap, originating from different Mel/TAP monomer ratios. DFT calculations showed that TAP doping and the resultant $\mathrm{C}$ incorporation into the PTI structure caused the VB shift to a more negative potential and reduces bandgap accordingly. This study attempted the $\mathrm{CN}$ synthesis in the presence of $\mathrm{KCC}-1$, resulting in beneficial effects to improve photocatalytic stability. The optimized synthesis yielded a HER photocatalyst with a remarkable AQE of $22.1 \pm 3 \%$ at $400 \mathrm{~nm}$ for solar to HER. The improved lifetime for the ground-state bleaching of the excited charge carriers was evidenced by time-resolved transient absorption spectroscopy of the optimized CN/KCC-1 photocatalyst, consistent with the higher photocatalytic performance than that of $\mathrm{CN}$ without KCC-1. A fibrous $\mathrm{CN}$ morphology coated with highly dispersed Pt nanoparticles was identified, likely providing effective interface between the metal and the semiconductor. The large exciton-binding energy calculated from DFT indicates that such architecture is necessary to obtain efficient exciton dissociation. Further studies are required to provide a better understanding of the silica effects in particular; nevertheless, this type of synthesis strategy enabled us to create a robust $\mathrm{CN}$ photocatalyst.

\section{ASSOCIATED CONTENT}

Supporting Information. Experimental procedures, methods, product characterization and computational details. This material is available free of charge via the Internet at http://pubs.acs.org.

\section{AUTHOR INFORMATION}

\section{Corresponding Author}

* Kazuhiro Takanabe. Mail address: 4700 KAUST, Thuwal,
23955-6900, Saudi Arabia. E-mail: kazuhi-
ro.takanabe@ kaust.edu.sa. Website: http://catec.kaust.edu.sa.

\section{Present Addresses}

\# Department of Physics, University of Mumbai, Mumbai-400098, India.

\section{ACKNOWLEDGMENTS}

The research reported in this work was supported by the King Abdullah University of Science and Technology. We are grateful to Dr. D. S. Dhawale, Mr. Angel T. Garcia-Esparza and Dr. A. A. Gurinov at KAUST for helping SEM, XPS and solid-state NMR studies, respectively. We are grateful to Dr. R. Dovesi and Dr. B. 
Lotsch for fruitful discussions. We acknowledge the IDRIS and SHAHEEN calculation centers for providing computational resources.

\section{ABBREVIATIONS}

Mel, Melamine; TAP, 2,4,6- Triaminopyrimidine; PTI, Polytriazine imide; AQE, Apparent quantum efficiency; DFT, Density functional theory; HER, Hydrogen evolution reaction; EDXA, Energy dispersive X-ray analysis; EELS, Electron energy loss spectroscopy; MAS NMR, Magic angle spinning nuclear magnetic resonance; HAADF-STEM, High-angle annular dark-field scanning transmission electron microscopy; CPHF, CoupledPerturbed Hartree-Fock; CB, Conduction band; VB, Valence band; DOS, Density of States.

\section{REFERENCES}

(1) Iwashina, K.; Iwase, A.; Ng, Y. H.; Amal, R.; Kudo, A. ZSchematic Water Splitting into $\mathrm{H}_{2}$ and $\mathrm{O}_{2}$ Using Metal Sulfide as a Hydrogen-Evolving Photocatalyst and Reduced Graphene Oxide as a Solid-State Electron Mediator. J. Am. Chem. Soc. 2015, 137, 604607.

(2) Osterloh, F. E. Inorganic Nanostructures for Photoelectrochemical and Photocatalytic Water Splitting. Chem. Soc. Rev. 2013, 42, 2294-2320.

(3) Lewis, N. S.; Nocera, D. G. Powering The Planet: Chemical Challenges in Solar Energy Utilization. Proc. Natl. Acad. Sci. USA 2006, 103, 15729-15735.

(4) Sun, Y.; Sun, J.; Long, J. R.; Yang, P.; Chang, C. J. Photocatalytic Generation of Hydrogen from Water Using A Cobalt Pentapyridine Complex in Combination with Molecular and Semiconductor Nanowire Photosensitizers. Chem. Sci. 2013, 4, 118-124.

(5) Eberle, U.; Felderhoff, M.; Schüth, F. Chemical and Physical Solutions for Hydrogen Storage Angew. Chem. Int. Ed. 2009, 48, $6608-6630$

(6) Cha, H. G.; Choi, K.-S. Combined Biomass Valorization and Hydrogen Production in a Photoelectrochemical Cell. Nature Chem. 2015, 7, 328-333.

(7) Chen, Y.; Lin, B.; Yu, W.; Yang, Y.; Bashir, S. M.; Wang, H.; Takanabe, K.; Idriss, H.; Basset, J.-M. Surface Functionalization of g$\mathrm{C}_{3} \mathrm{~N}_{4}$ : Molecular-Level Design of Noble-Metal-Free Hydrogen Evolution Photocatalysts. Chem. Eur.J. 2015, 21, $10290-10295$.

(8) Maeda, K.; Eguchi, M.; Lee, S.-H. A.; Youngblood, W. J.; Hata, H.; Mallouk, T. E. Photocatalytic Hydrogen Evolution from Hexaniobate Nanoscrolls and Calcium Niobate Nanosheets Sensitized by Ruthenium(II) Bipyridyl Complexes. J. Phys. Chem. C 2009, 113, 7962-7969.

(9) Alenzi, N.; Liao, W.-S.; Cremer, P. S.; Sanchez-Torres, V.; Wood, T. K.; Ehlig-Economides, C.; Cheng, Z. Photoelectrochemical Hydrogen Production from Water/Methanol Decomposition Using

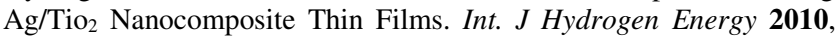
$35,11768-11775$

(10) Bren, K. L. Multidisciplinary Approaches to Solar Hydrogen. Interface Focus, 2015, 5, 20140091.

(11) Martindale, B. C. M.; Hutton, G. A. M.; Caputo, C. A.; Reisner, E. Solar Hydrogen Production Using Carbon Quantum Dots and a Molecular Nickel Catalyst. J. Am. Chem. Soc. 2015, 137, 60186025 .

(12) Sprick, R. S.; Jiang, J.-X.; Bonillo, B.; Ren, S.; Ratvijitvech, T.; Guiglion, P.; Zwijnenburg, M. A.; Adams, D. J.; Cooper, A. I. Tunable Organic Photocatalysts for Visible-Light-Driven Hydrogen Evolution. J. Am. Chem. Soc. 2015, 137, 3265-3270.

(13) Wang, X.; Maeda, K.; Thomas, A.; Takanabe, K.; Xin, G.; Carlsson, J. M.; Domen, K.; Antonietti, M. A Metal-Free Polymeric Photocatalyst for Hydrogen Production from Water Under Visible Light. Nat. Mater. 2009, 8, 76-80.

(14) Lau, V. W.-H.; Mesch, M. B.; Duppel, V.; Blum, V.; Senker, J.; Lotsch, B. V. Low-Molecular-Weight Carbon Nitrides for Solar Hydrogen Evolution. J. Am. Chem. Soc. 2015, 137, 1064-1072.
(15) Goglio, G.; Foy, D.; Demazeau, G. State of Art and Recent Trends in Bulk Carbon Nitrides Synthesis. Mater. Sci. Eng. 2008, 58, 195-227.

(16) Martin, D. J.; Reardon, P. J. T.; Moniz, S. J. A.; Tang, J.-W. Visible Light-Driven Pure Water Splitting by a Nature-Inspired Organic Semiconductor-Based System. J. Am. Chem. Soc. 2014, 136, 12568-12571.

(17) Kroke, E.; Schwarz, M. Novel Group 14 Nitrides. Coord. Chem. Rev. 2004, 248, 493-532.

(18) Kroke, E.; Schwarz, M.; Hovarth-Bordon, E.; Kroll, P.; Noll, B.; Norman, A. D. Tri-S-Triazine Derivatives. Part I. from TrichloroTri-S-Triazine to Graphitic $\mathrm{C}_{3} \mathrm{~N}_{4}$ Structures. New J. Chem. 2002, 26, $508-512$.

(19) Liu, X.; Fechler, N.; Antonietti, M. Salt Melt Synthesis of Ceramics, Semiconductors and Carbon Nanostructures. Chem. Soc. Rev. 2013, 42, 8237-8265.

(20) Algara-Siller, G.; Severin, N.; Chong, S. Y.; Björkman, T.; Palgrave, R. G.; Laybourn, A.; Antonietti, M.; Khimyak, Y. Z.; Krasheninnikov, A. V.; Rabe, J. P.; Kaiser, U.; Cooper, A. I.; Thomas, A.; Bojdys, M. J. Triazine-Based Graphitic Carbon Nitride: a Two-Dimensional Semiconductor. Angew. Chem. Int. Ed. 2014, 53, $7450-7455$.

(21) Bhunia, M. K.; Yamauchi, K.; Takanabe, K. Harvesting Solar Light with Crystalline Carbon Nitrides for Efficient Photocatalytic Hydrogen Evolution. Angew. Chem. Int. Ed. 2014, 53, 11001-11005.

(22) Takanabe, K. Solar Water Splitting Using Semiconductor Photocatalyst Powders. Top. Curr. Chem. 2016, 371, 73-103.

(23) Sun, J.; Zhang, J.; Zhang, M.; Antonietti, M.; Fu, X.; Wang, X. Bioinspired Hollow Semiconductor Nanospheres as Photosynthetic Nanoparticles. Nat. Commun. 2012, 3, 1139.

(24) Shalom, M.; Inal, S.; Fettkenhauer, C.; Neher, D.; Antonietti, M. Improving Carbon Nitride Photocatalysis by Supramolecular Preorganization of Monomers. J. Am. Chem. Soc. 2013, 135, $7118-7121$

(25) Schwinghammer, K.; Mesch, M. B.; Duppel, V.; Ziegler, C.; Senker, J.; Lotsch, B. V. Crystalline Carbon Nitride Nanosheets for Improved Visible-Light Hydrogen Evolution. J. Am. Chem. Soc. 2014, 136, 1730-1733.

(26) Hu, J.-S.; Ren, L.-L.; Guo, Y.-G.; Liang, Cao, A.-M.; Wan, L.-J.; Bai, C.-L. Mass Production and High Photocatalytic Activity of ZnS Nanoporous Nanoparticles. Angew. Chem. Int. Ed. 2005, 44 1269-1273.

(27) Oesterling, I.; Müllen, K. Multichromophoric Polyphenylene Dendrimers: Toward Brilliant Light Emitters with an Increased Number of Fluorophores. J. Am. Chem. Soc. 2007, 129, 4595-4605.

(28) Jun, Y.-S.; Park, J.; Lee, S. U.; Thomas, A.; Hong, W. H.; Stucky, G. D. Three-Dimensional Macroscopic Assemblies of LowDimensional Carbon Nitrides for Enhanced Hydrogen Evolution. Angew. Chem. Int. Ed. 2013, 52, 11083-11087.

(29) Adronov, A.; Fréchet, J. M. J. Light-harvesting dendrimers. Chem. Commun. 2000, 1701-1710.

(30) Huynh, M. H. V.; Hiskey, M. A.; Archuleta, J. G.; Roemer, E. L. Preparation of Nitrogen-Rich Nanolayered, Nanoclustered, and Nanodendritic Carbon Nitrides. Angew. Chem. Int. Ed. 2005, 44, 737739.

(31) Nurlaela, E.; Ould-Chikh, S.; Harb, M.; del Gobbo, S.; Aouine, M.; Puzenat, E.; Sautet, P.; Domen, K.; Basset, J.-M.; Takanabe, K. Critical Role of the Semiconductor-Electrolyte Interface in Photocatalytic Performance for Water-Splitting Reactions Using $\mathrm{Ta}_{3} \mathrm{~N}_{5}$ Particles. Chem. Mater. 2014, 26, 4812- 4825.

(32) Kandiel, T. A.; Anjum, D. H.; Sautet, P.; Le Bahers, T.; Takanabe, K. Electronic Structure and Photocatalytic Activity of Wurtzite $\mathrm{Cu}^{-} \mathrm{Ga}^{-} \mathrm{S}$ Nanocrystals and Their Zn Substitution. J. Mater. Chem. A 2015, 3, 8896-8904.

(33) Heyd, J.; Scuseria, G. E.; Ernzerhof, M. Hybrid Functionals Based on A Screened Coulomb Potential. J. Chem. Phys. 2006, 124, 219906.

(34) Le Bahers, T.; Rérat, M.; Sautet, P. Semiconductors Used in Photovoltaic and Photocatalytic Devices: Assessing Fundamental Properties from DFT. J. Phys. Chem. C 2014, 118, 5997-6008. 
(35) Zhang, J.; Zhang, M.; Yang, C.; Wang, X. Nanospherical Carbon Nitride Frameworks with Sharp Edges Accelerating Charge Collection and Separation at a Soft Photocatalytic Interface. Adv. Mater. 2014, 26, 4121-4126.

(36) Zheng, Y.; Lin, L.; Ye, X.; Guo, F.; Wang, X. Helical Graphitic Carbon Nitrides with Photocatalytic and Optical Activities. Angew. Chem. Int. Ed. 2014, 53, 11926-11930.

(37) Zheng, D.; Pang, C.; Liu, Y.; Wang, X. Shell-Engineering of Hollow g- $\mathrm{C}_{3} \mathrm{~N}_{4}$ Nanospheres via Copolymerization for Photocatalytic Hydrogen Evolution. Chem.Commun. 2015, 51, 9706-9709.

(38) Vinu, A.; Srinivasu, P.; Sawant, D. P.; Mori, T.; Ariga, K.; Chang, J.-S.; Jhung, S.-H.; Balasubramanian, V. V.; Hwang, Y. K. Three-Dimensional Cage Type Mesoporous CN-Based Hybrid Material with Very High Surface Area and Pore Volume. Chem. Mater. 2007, 19, 4367-4372.

(39) Polshettiwar, V.; Cha, D.; Zhang, X.; Basset, J. M. HighSurface-Area Silica Nanospheres (KCC-1) with a Fibrous Morphology. Angew. Chem. Int. Ed. 2010, 49, 9652-9656.

(40) Shalom, M.; Inal, S.; Neherb, D.; Antonietti, M. SiO $2 /$ Carbon Nitride Composite Materials: The Role of Surfaces for Enhanced Photocatalysis. Catal. Today 2014, 225, 185-190.

(41) Xiao, P.; Zhao,Y.; Wang, T.; Zhan, Y.; Wang, H.; Li, J.; Thomas, A.; Zhu, J. Polymeric Carbon Nitride/Mesoporous Silica Composites as Catalyst Support for Au and Pt Nanoparticles. Chem. Eur. J. 2014, 20, 2872-2878.

(42) Liu, X.; Zhao, L.; Domen, K.; Takanabe, K. Photocatalytic Hydrogen Production Using Visible-Light-Responsive $\mathrm{Ta}_{3} \mathrm{~N}_{5}$ Photocatalyst Supported on Monodisperse Spherical $\mathrm{SiO}_{2}$ Particulates. Mater. Res. Bull. 2014, 49, 58-65.

(43) Sun, J.; Yu, W.; Usman, A.; Isimjan, T. T.; DGobbo, S.; Alarousu, E.; Takanabe, K.; Mohammed, O. F. Generation of Multiple Excitons in Ag2S Quantum Dots: Single High-Energy versus Multiple-Photon Excitation. J. Phys. Chem. Lett. 2014, 5, 659-665.

(44) Dovesi, R.; Saunders, V. R.; Roetti, C.; Orlando, R.; ZicovichWilson, C. M.; Pascale, F.; Civalleri, B.; Doll, K.; Harrison, N. M.; Bush, I. J.; D'Arco, P.; Llunell, M.; Causà, M.; Noël, Y. CRYSTAL14 User's Manual (University of Torino, Torino), 2014, CRYSTAL14 User's Manual (University of Torino).

(45) Dovesi, R.; Orlando, R.; Erba, A.; Zicovich-Wilson, C. M.; Civalleri, B.; Casassa, S.; Maschio, L.; Ferrabone, M.; De La Pierre, M.; D’Arco, P.; Noël, Y.; Causà, M.; Rérat, M.; Kirtman, B. CRYSTAL14: A Program for the Ab Initio Investigation of Crystalline Solids. Int. J. Quantum Chem. 2014, 114, 1287-1317.

(46) Monkhorst, H. J.; Pack, J. D. Special Points for BrillouinZone Integrations. Phys. Rev. B 1976, 13, 5188-5192.

(47) Grimme, S. Semiempirical GGA-Type Density Functional Constructed with a Long-Range Dispersion Correction. J. Comput. Chem. 2006, 27, 1787-1799.

(48) Ando, T.; Fowler, B.; Stern, F. Electronic Properties of TwoDimensional Systems. Rev. Mod. Phys. 1982, 54, 437.

(49) Noel, Y.; Zicovich-Wilson, C.; Civalleri, B.; D’Arco, P.; Dovesi, R. Polarization Properties of Zno And Beo. Phys. Rev. B 2001, 65, 014111.

(50) Ferrero, M.; Rérat, M.; Orlando, R.; Dovesi, R. Coupled Perturbed Hartree-Fock for Periodic Systems: The Role of Symmetry and Related Computational Aspects. J. Chem. Phys. 2008, 128, 014110.

(51) Ferrero, M.; Rérat, M.; Orlando, R.; Dovesi, R. The Calculation of Static Polarizabilities of 1-3D Periodic Compounds. The Implementation in The Crystal Code. J. Comput. Chem. 2007, 29, $1450-1459$.

(52) Ferrero, M.; Rérat, M.; Kirtman, B.; Dovesi, R. Calculation of First and Second Static Hyperpolarizabilities of One- to ThreeDimensional Periodic Compounds. Implementation in the CRYSTAL Code. J. Chem. Phys. 2008, 129, 244110.

(53) Stevanović, V.; Lany, S.; Ginley, D. S.; Tumas, W.; Zunger, A. Assessing Capability of Semiconductors to Split Water Using Ionization Potentials and Electron Affinities Only. Phys. Chem. Chem. Phys. 2014, 16, 3706-3714.

(54) Ham, Y.; Maeda, K.; Cha, D.; Takanabe, K.; Domen, K. Synthesis and Photocatalytic Activity of Poly(triazine imide). Chem. Asian J. 2013, 8, $218-224$.
(55) Deifallah, M.; McMillan, P. F.; Corà, F. Electronic and Structural Properties of Two-Dimensional Carbon Nitride Graphenes. J. Phys. Chem. C 2008, 112, 5447-5453.

(56) Chong, S. Y.; Jones, J. T. A.; Khimyak, Y. Z.; Cooper, A. I.; Thomas, A.; Antonietti, M.; Bojdys, M. J. Tuning of Gallery Heights in a Crystalline 2D Carbon Nitride Network. J. Mater. Chem. A, 2013, 1, 1102-1107.

(57) Wirnhier, E.; Döblinger, M.; Gunzelmann, D.; Senker, J.; Lotsch, B.V.; Schnick, W. Poly(triazine imide) with Intercalation of Lithium and Chloride Ions $\left[\left(\mathrm{C}_{3} \mathrm{~N}_{3}\right)_{2}\left(\mathrm{NH}_{\mathrm{x}} \mathrm{Li}_{1-\mathrm{x}}\right)_{3} \cdot \mathrm{LiCl}\right]$ : A Crystalline 2D Carbon Nitride Network. Chem. Eur. J. 2011, 17, 3213-3221.

(58) Xu, H.; Yan, J.; She, X.; Xu, L.; Xia, J.; Xu, Y.; Song, Y.; Huang, L.; Li, H. Graphene-Analogue Carbon Nitride: Novel Exfoliation Synthesis and Its Application in Photocatalysis and Photoelectrochemical Selective Detection of Trace Amount of $\mathrm{Cu}^{2+}$. Nanoscale, 2014, 6, 1406-1415.

(59) Liu, G.; Niu, P.; Sun, C.; Smith, S. C.; Chen, Z.; Qing, G.; Lu, M.; Cheng, H. Unique Electronic Structure Induced High Photoreactivity of Sulfur-Doped Graphitic $\mathrm{C}_{3} \mathrm{~N}_{4}$. J. Am. Chem. Soc. 2010, 132, $11642-11648$.

(60) Liu, G.; Wang, L.; Yang, H. G.; Cheng, H.-M.; (Max) Lu, G. Q. Titania-Based Photocatalysts-Crystal Growth, Doping and Heterostructuring. J. Mater. Chem. 2010, 20, 831-843.

(61) Butler, S. Z.; Hollen, S. M.; Cao, L.; Cui, Y.; Gupta, J. A.; Gutiérrez, H. R.; Heinz, T. F.; Hong, S. S.; Huang, J.; Ismach, A. F.; Johnston-Halperin, E.; Kuno, M.; Plashnitsa, V. V.; Robinson, R. D.; Ruoff, R. S.; Salahuddin, S.; Shan, J.; Shi, L.; Spencer, M. G.; Terrones, M.; Windl, W.; Goldberge, J. E. Progress, Challenges, and Opportunities in Two-Dimensional Materials Beyond Graphene. ACS Nano. 2013, 7, 2898-2926.

(62) Melissen, S.; Labat, F.; Sautet, P.; Le Bahers, T. Electronic Properties of $\mathrm{PbX}_{3} \mathrm{CH}_{3} \mathrm{NH}_{3}(\mathrm{X}=\mathrm{Cl}, \mathrm{Br}$, I) Compounds for Photovoltaic and Photocatalytic Applications. Phys. Chem. Chem. Phys. 2015, 17, 2199-2209.

(63) Bao, J. L.; Yu, H. S.; Duanmu, K.; Makeev, M. A.; Xu, X.; Truhlar, D. G. Density Functional Theory of the Water Splitting Reaction on $\mathrm{Fe}(0)$ : Comparison of Local and Non local Correlation Functionals. ACS Catal. 2015, 5, 2070-2080.

(64) X.-F. He, Excitons in Anisotropic Solids: The Model of Fractional-Dimensional Space. Phys. Rev. B 1991, 43, 2063.

(65) Blom, P. W. M.; Mihailetchi, V. D.; Koster, L. J. A.; Markov, D.E. Device Physics of Polymer: Fullerene Bulk Heterojunction Solar Cells. Adv. Mater. 2007, 19, 1551-1566.

(66) Wei, W.; Jacob, T. Strong Excitonic Effects in the Optical Properties of Graphitic Carbon Nitride g- $\mathrm{C}_{3} \mathrm{~N}_{4}$ from First Principles. Phys. Rev. B 2013, 085202.

(67) El-Ballouli, A. a. O.; Alarousu, E.; Bernardi, M.; Aly, S. M.; Lagrow, A. P.; Bakr, O. M.; Mohammed, O. F. Quantum Confinement-Tunable Ultrafast Charge Transfer at the PbS Quantum Dot and Phenyl-C-61-butyric Acid Methyl Ester Interface. J. Am. Chem. Soc. 2014, 136, 6952-6959;

(68) Aly, S. M.; Parida, M. R.; Alarousu, E.; Mohammed, O. F. Ultrafast electron injection at the cationic porphyrin- graphene interface assisted by molecular flattening. Chem Commun. 2014, 50, 1045210455.

(69) Parida, M. R.; Aly, S. M.; Alarousu, E.; Sridharan, A.; Nagaraju, D. H.; Alshareef, H. N.; Mohammed, O. F. To What Extent Can Charge Localization Influence Electron Injection Efficiency at Graphene-Porphyrin Interfaces? Phys. Chem. Chem. Phys. 2015, 17, 14513-14517.

(70) Mohammed, O. F.; Banerji, N.; Lang, B.; Nibbering, E. T. J.; Vauthey, E. Photoinduced Bimolecular Electron Transfer Investigated by Femtosecond Time-Resolved Infrared Spectroscopy. J. Phys. Chem. A 2006, 110, 13676-13680.

(71) Du, A.; Sanvito, S.; Li, Z.; Wang, D.; Jiao, Y.; Liao, T.; Sun, Q.; Ng, Y. H.; Zhu, Z.; Amal, R.; Smith, S. C. Hybrid Graphene and Graphitic Carbon Nitride Nanocomposite: Gap Opening, ElectronHole Puddle, Interfacial Charge Transfer, and Enhanced Visible Light Response. J. Am. Chem. Soc. 2012, 134, 4393-4397. 
(72) Mikhnenko, O. V.; Azimi, H.; Scharber, M.; Morana, M.; Blom, P. W. M.; Loi, M. A. Exciton Diffusion Length in Narrow Bandgap Polymers. Energy Environ. Sci. 2012, 5, 6960-6965.

(73) Cunningham, P. D.; Michael Hayden, L. Carrier Dynamics Resulting from Above and Below Gap Excitation of P3HT and P3HT/PCBM Investigated by Optical-Pump Terahertz-Probe Spectroscopy. J. Phys. Chem. C 2008, 112, 7928-7935.
(74) Huang, Y.; Kramer, E. J.; Heeger, A. J.; Bazan, G. C. Bulk Heterojunction Solar Cells: Morphology and Performance Relationships. Chem. Rev. 2014, 114, 7006-7043.

(75) Singh, R. B.; Matsuzaki, H.; Suzuki, Y.; Seki, K.; Minegishi, T.; Hisatomi, T.; Domen, K.; Furube, A. Trapped State Sensitive Kinetics in LaTiO2N Solid Photocatalyst with and without Cocatalyst Loading. J. Am. Chem. Soc. 2014, 136, 17324-17331. 
1

2

3

4

5

6

10

11

12

13

14

15

16

17

18

19

20

21

22

23

24

25

26

27

28

29

30

31

32

33

34

35

36

37

38

39

40

41

42

43

44

45

46

47

48

49

50

51

52

53

54

55

56

57

58

59

60

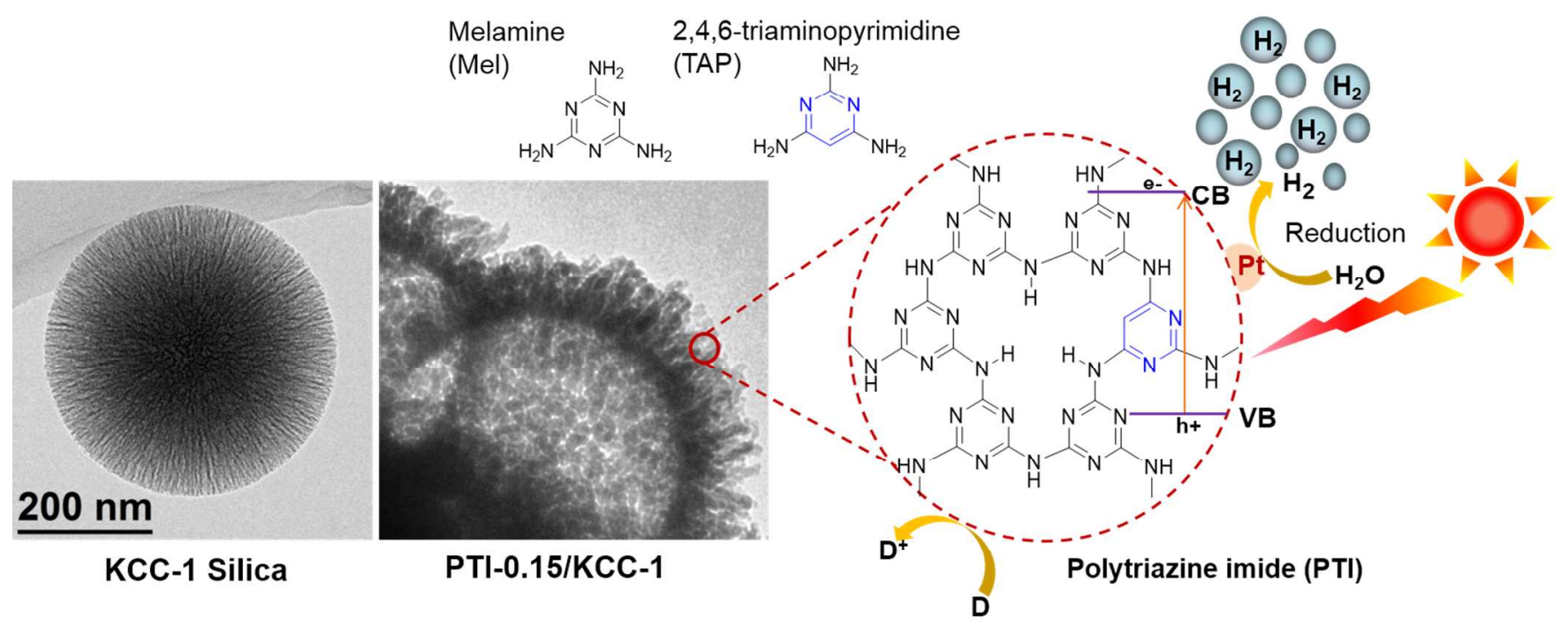




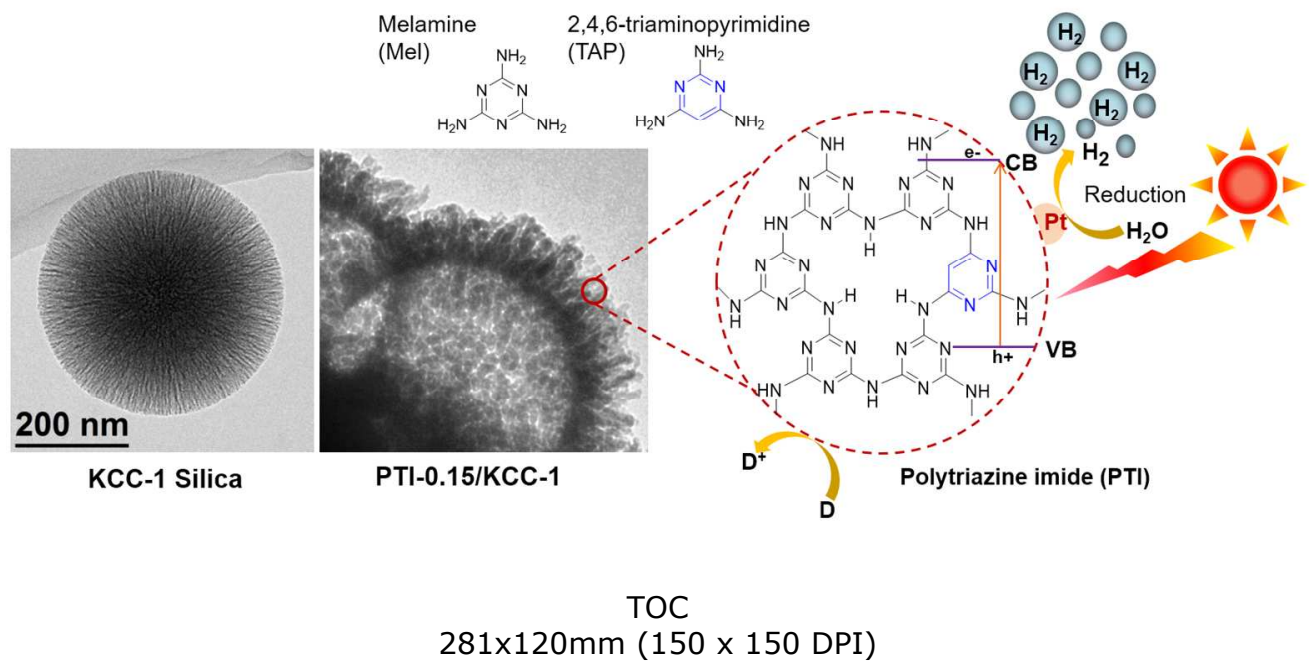

